\title{
PENGELOLAAN ORGANISASI KEPENGURUSAN YANG EFEKTIF DI TPA PUTRA BANI, KELURAHAN BENDA BARU, PAMULANG, TANGERANG SELATAN
}

\author{
Adji Widodo'), Gojali Supiandi' ${ }^{2)}$, Siti Nuraidawati ${ }^{3)}$, Buchari E. Satiaputra ${ }^{4}$, \\ Chotamul Fajri ${ }^{5)}$
}

1,2,3,4,5 Program Studi Manajemen, Fakultas Ekonomi, Universitas Pamulang

\begin{abstract}
ABSTRAK
Tujuan dari kegiatan pengabdian kepada masyarakat ini adalah untuk mengarahkan pengurus agar dapat mengelola TPA Putra Bani yang efektif di lingkungan Kelurahan Benda Baru, Pamulang. Peserta pengabdian ini adalah siswa, orang tua, pengurus TPA Putra Bani, ulama, dan pakar pendidikan di wilayah setempat. Metode pengabdian yang digunakan adalah metode survey dan penyuluhan secara langsung dengan memberikan kiat-kiat orang tua agar dapat memotivasi siswa untuk semangat belajar Al-Qur'an, dimulai dari kebiasaan saat berada di rumah, pelatihan yang ditujukan kepada pengurus TPA agar memiliki wawasan, cara pemecahan masalah, semangat kerjasama dan berjiwa kepemimpinan. Serta dilakukan tanya jawab kepada siswa, orang tua, pengurus TPA, ulama, serta pakar pendidikan. Kesimpulannya adalah bahwa kegiatan ini telah memberikan kontribusi yang positif bagi masyarakat dengan pengelolaan organisasi yang efektif terhadap Taman Pendidikan AlQur'an Putra Bani di kemudian hari, yaitu telah terbentuk susunan kepengurusan TPA, pendataan siswa dari usia TK, SD, SMP, dan SMA. Juga dilakukan penjadwalan rapat lima unsur pendidikan, sosialisasi kurikulum dan target pembelajaran.
\end{abstract}

Kata Kunci : Kepengurusan yang efekif, TPA Putra Bani, Lima unsur pendidikan

\begin{abstract}
The purpose of this community service activity is to direct the management to be able to effectively manage the Putra Bani TPA in the Benda Baru Village, Pamulang. Participants of this service are students, parents, TPA management of Putra Bani, scholars, and education experts in the local area. The dedication method used is a survey method and direct counseling by giving parents tips in order to motivate students to enthusiasm for learning the Qur'an, starting from the habit when at home, training aimed at TPA administrators to have insight, ways problem solving, cooperation spirit and leadership. As well as question and answer to students, parents, TPA administrators, scholars, and education experts. The conclusion is that this activity has contributed positively to the community with effective organizational management of the Putra Bani Al-Qur'an Education Park in the future, namely the management structure of the TPA, data collection of students from kindergarten, elementary, junior high, and high school. Also scheduling meetings of the five elements of education, curriculum socialization and learning targets.
\end{abstract}

Keywords: Effective management, TPA Putra Bani, Five elements of education 


\section{PENDAHULUAN}

Taman Pendidikan Al-Qur'an (TPA) "Putra Bani” berada di Perumahan Makadam, RT 04 RW 02, Kelurahan Benda Baru, Kecamatan Pamulang. TPA ini tepatnya berada di rumah milik H. Buchari, yaitu salah satu tokoh masyarakat di perumahan tersebut. Selain terdapat sarana rekreasi kolam dan Klinik herbal, juga menyediakan musholah untuk digunakan pengajian bagi anak-anak usia dini, maupun usia dewasa. Kegiatan belajar Al-Qur'an berjalan setiap sore hari hingga menjelang Magrib. Anak-anak siswa TPA berasal baik dari lingkungan terdekat, dan ada yang berasal dari luar RT setempat.

Kegiatan TPA hingga saat ini sudah berjalan tetapi terdapat beberapa hal yang memerlukan pembenahan agar dapat lebih tertib dan lancar ke depannya. Yang pertama, susunan kepengurusan belum dibentuk, diharapkan pada kegiatan pengabdian kepada masyarakat ini dapat diusulkan untuk dibentuk susunan pengurus TPA. Kedua, perlunya pencatatan lebih rinci berapa siswa yang terbagi di dalam kelompok umur, mulai dari TK, SD, SMP, maupun SMA. Ketiga, pentingnya sosialisasi kurikulum pendidikan TPA kepada orang tua siswa, agar dapat turut memantau dan mendorong semangat belajar siswa. Keempat, pentingnya penjadwalan rapat berkala antara pengurus TPA dan orang tua dan pakar pendidik yang disebut Lima Unsur Pendidikan.

Dengan adanya format kegiatan yang baik diharapkan dapat memotivasi siswa maupun dukungan dari orang tuanya. Untuk tercapainya tujuan belajar mengajar di TPA memerlukan kerja sama yang baik terutama dari lima unsur pendidikan yaitu, siswa, orang tua, pengajar, pengurus TPA, dan ahli pendidik.

Melihat kondisi seperti di atas maka melalui Pengabdian kepada masyarakat kali ini, para dosen Universitas Pamulang ingin berkontribusi memberikan masukan agar terciptanya perangkat TPA yaitu susunan pengurus TPA, pencatatan siswa sesuai kelompok umur, pengkajian dan sosialisasi program kurikulum pendidikan TPA, serta memastikan adanya jadwal rapat berkala Lima unsur pendidikan.dan jadwal acara kegiatan TPA. Dengan adanya program kegiatan TPA yang terstruktur dan rapih, diharapkan tujuan dan sasaran utama dapat terselenggaranya pendidikan yang nyaman, tertib, serta memenuhi kriteria kurikulum dan menghasilkan siswa yang berhasil dan cakap serta terampil di dalam menangkap dan menerapkan cara membaca serta mengaplikasikan ilmu agama Islam dengan baik. Tujuan pendidikan TPA Putra Bani yaitu meraih Tri Sukses Generus yaitu, untuk mendidik siswa yang Alim, Faqih dan Berakhlaqul Karimah.

Tujuan umum kegiatan pengabdian kepada masyarakat adalah untuk memberikan pengarahan kepada pengurus agar dapat mengelola TPA Putra Bani yang efektif di lingkungan Kelurahan Benda Baru, Pamulang. Adapun tujuan kegiatan pengabdian secara khusus adalah :

1). Untuk mengarahkan pembentukan susunan pengurus TPA Putra Bani di wilayah Kelurahan Benda Baru

2). Untuk membantu pendataan siswa sesuai dengan kelompok umur TK, SD, SMP, SMA

3). Untuk membantu sosialisasi kurikulum pendidikan kepada orang tua siswa, agar dapat membantu memantau peningkatan hasil belajar

4). Untuk membantu pengurus TPA melakukan penjadwalaan rapat Lima Unsur, yang terdiri dari Siswa, Orang tua, Pengurus TPA, Ulama dan Pakar Pendidikan. 
Kegiatan penyuluhan dan pelatihan disampaikan kepada seluruh pihak terkait yaitu siswa, orang tua, pengurus TPA, dan pakar pendidikan, yang dikemas dengan nama kegiatan "Pengelolaan Organisasi Kepengurusan Yang Efektif Di TPA Putra Bani, Kelurahan Benda Baru, Kecamatan Pamulang, Tangerang Selatan - Banten". Alur pemecahan masalah dijelaskan pada Gambar 1. di bawah ini :

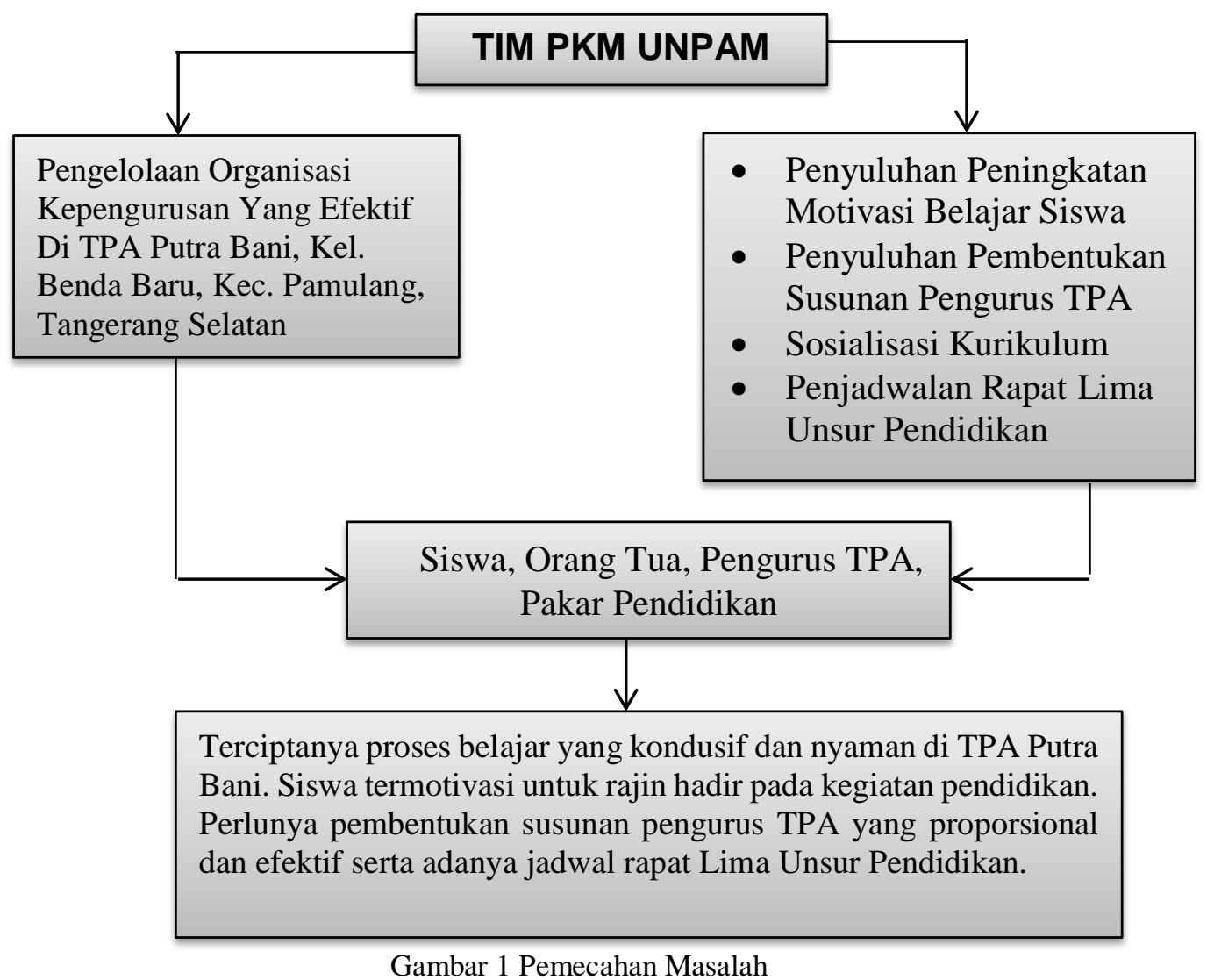

Motivasi merupakan kebutuhan setiap orang untuk mencapai kebaikan dalam berbagai hal. Motivasi siswa dalam belajar AL-Qur'an merupakan mesin penggerak sehingga melahirkan keinginan untuk belajar Al-Qur'an. Peran orang tua sangat penting di dalam motivasi anak pada masa perkembang dan pertumbuhan dalam belajar AlQur'an.

Landasan hukum di dalam menjalankan Taman pendidikan Al-Qur'an (TPA) terdapat pada Undang-undang Pendidikan No. 2 Tahun 1989, yaitu tentang "Sistem Pendidikan Nasional" Bab II pasal 4. Dijelaskan bahwa tujuan Pendidikan Nasional adalah menjadi manusia yang beriman dan bertaqwa. Diperkuat pada Surat Keputusan Bersama (SKB) Menteri Dalam Negeri dan Menteri Agama RI No. 128 dan 44 A Tahun 1982 yang menyatakan bahwa " Dalam rangka penghayatan Al-Qur'an untuk kehidupan diperlukan kemampuan baca dan tulis Al-Qur'an yang baik.

TPA merupakan lembaga pendidikan non formal yang mempelajari cara beribadah di dalam agama Islam yang mengacu pada sumber Al-Qur'an. Pada pelaksanaanya akan dikelompokkan sesuai dengan tingkatan usia anak, yaitu PAUD, TK, SD. Namun pada TPA Putra Bani juga terdapat siswa dengan kelompok umur SMP dan SMA. 
Materi pengajarannya disesuaikan dengan kurikulum baik pengetahuan dasar agama, karakter dan keterampilan dalam beribadah. Pelajaran pada TPA sifatnya melengkapi apa yang sudah diajarkan pada sekolah formal. Tetapi siswa akan mendapatkan kesempatan untuk mendalami kemampuan membaca, menulis Al-Qur'an, bahkan belajar terhadap penjelasan beberapa Hadits sebagai Sunnah Rasulullah.

Sasaran program pengabdian adalah memotivasi siswa, orang tua, juga pengurus TPA Putra Bani di Kelurahan Benda Baru, Kecamatan Pamulang, Tangerang Selatan, yang berjumlah 30 orang.

\section{METODE PELAKSANAAN}

Metode yang digunakan pada kegiatan pengabdian masyarakat ini adalah :

1). Penyuluhan dengan memberikan kiat-kiat kepada orang tua agar dapat memotivasi siswa untuk semangat belajar Al-Qur'an, dimulai dari hal-hal yang kecil di rumah

2). Pelatihan ditujukan kepada pengurus TPA agar dapat berwawasan lebih, bagaimana pemecahan masalah, semangat kerjasama dan berjiwa kepemimpinan

3). Tanya jawab dengan siswa, orang tua, pengurus TPA, ulama, serta pakar pendidikan

Evaluasi kegiatan dilakukan setelah kegiatan penyuluhan dan pelatihan kepada siswa, orang tua, pengajra TPA, yaitu dengan cara mengisi data yang disiapkan oleh Tim PKM terkait bagaimanakah tanggapan para peserta terhadap kegiatan PKM yang dilakukan oleh Tim Dosen Manajemen Universitas Pamulang.

\subsection{Tempat dan Waktu}

Tempat : Musholah Putra Bani, Komplek Makadam, RT 04 RW 02, Kelurahan Benda Baru, Kecamatan Pamulang, Tangerang Selatan.

Waktu : Tgl. 9 Agustus 2019, tahap survey lokasi dan perkenalan tim pengabdi kepada pemilik TPA Putra Bani. Pemasangan spanduk, sound system dan peralatan lain.

Tgl. 10 Agustus 2019, tahap penyuluhan dan pengabdian kepada masyarakat.

\subsection{Jadwal Kegiatan}

Rencana jadwal dari awal hingga pelaporan kegiatan pengabdian sebagai berikut :

Tabel 1 Jadwal Kegiatan

\begin{tabular}{|c|l|c|c|c|c|}
\hline \multirow{2}{*}{ NO } & \multicolumn{1}{|c|}{ Kegiatan } & \multicolumn{3}{|c|}{ Waktu (dalam bulan) } \\
\cline { 4 - 6 } & & I & II & III & IV \\
\hline 1 & Perijinan & & & & \\
\hline 2 & Observasi Awal & & & \\
\hline 3 & Pelatihan Anggota Tim & & & & \\
\hline 4 & Sosialisasi Program & & & \\
\hline 5 & $\begin{array}{l}\text { Pelaksanaan penyuluhan dan } \\
\text { pelatihan di TPA Putra Bani }\end{array}$ & & & \\
\hline 6 & Evaluasi penyuluhan dan pelatihan & & & & \\
\hline
\end{tabular}




\begin{tabular}{|c|c|c|c|c|c|}
\hline \multirow[t]{2}{*}{ NO } & \multirow[t]{2}{*}{ Kegiatan } & \multicolumn{4}{|c|}{ Waktu (dalam bulan) } \\
\hline & & I & II & III & IV \\
\hline 7 & Pengolahan Data & & & & \\
\hline 8 & Analisis Data & & & & \\
\hline 9 & Perumusan Hasil \& Kesimpulan & & & & \\
\hline 10 & Evaluasi Program & & & & \\
\hline 11 & Publikasi & & & & \\
\hline 12 & Pelaporan & & & & \\
\hline
\end{tabular}

\section{HASIL DAN PEMBAHASAN}

\subsection{Pembentukan Pengurus TPA Putra Bani}

Dari hasil acara Pengabdian kepada masyarakat, dosen Universitas Pamulang memberikan arahan untuk pembentukan susunan pengurus TPA Putra Bani, agar ke depannya organisasi dapat berjalan lebih ejektif. Setelah disepakati maka susunan pengurus TPA adalah sebagai berikut :

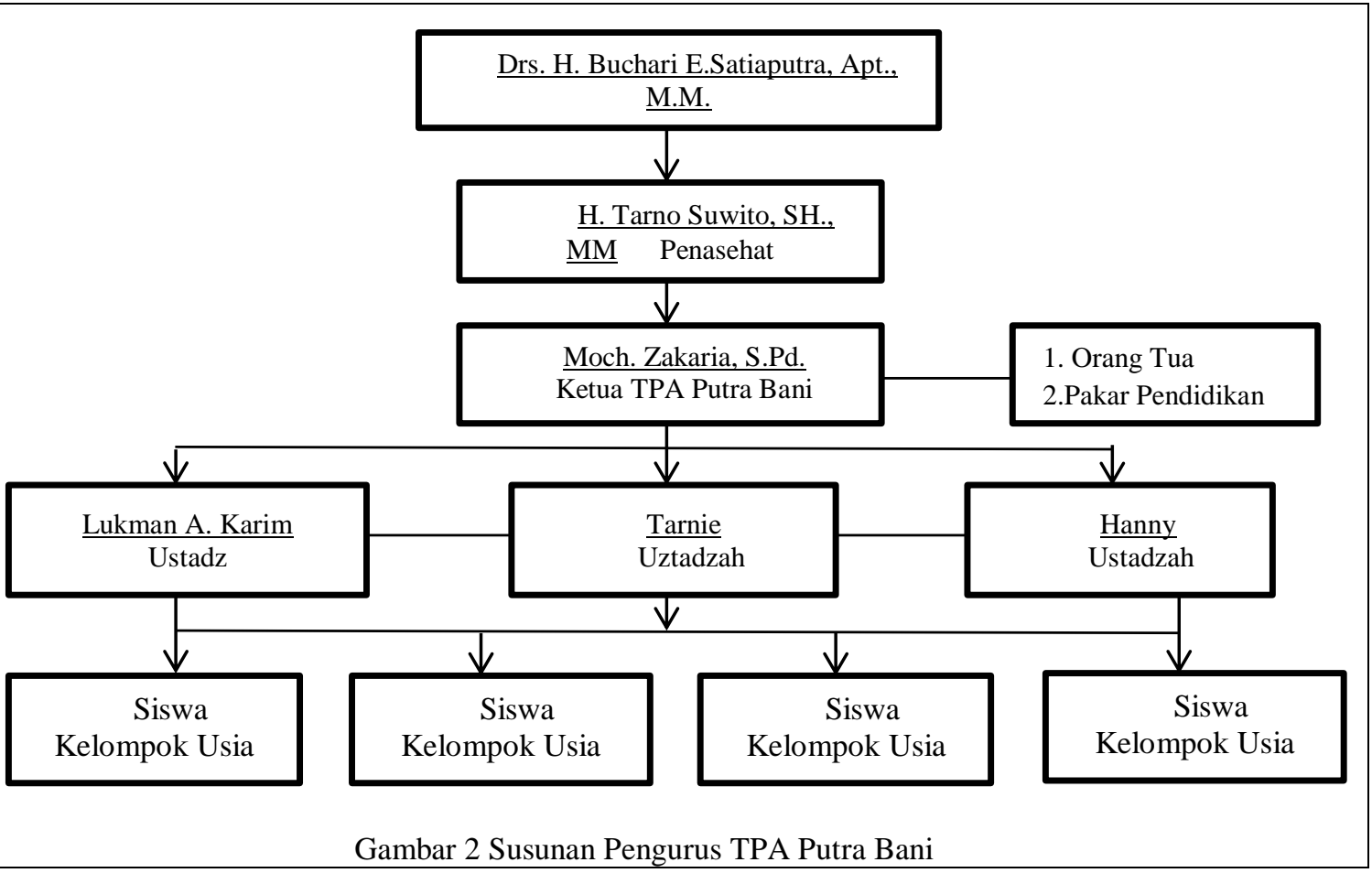

Ketua yayasan adalah H. Buchari E. Satiaputra sebagai pemilik sarana musolah Putra Bani, yang telah memberikan fasilitas tempat serta akomodaasi lainnya. Adapun Sebagai penasihat adalah H. Tarno Suwito adalah tokoh masyarakat di kelurahan Benda Baru. Ketua TPA ditunjuk Moch. Zakaria yang sudah beberapa tahun sudah meluangkan waktunya mendedikasikan ilmu Al-Qur'an kepada para siswa di Musolah Putra Bani. Sebagai pengajar ada empat orang yaitu ustadz Lukman Abdul Karim, Ustadzah Tarnie, dan Ustadzah Hanny, serta ditambah Moch. Zakaria membantu pengajaran jika ada salah satu pengajar berhalangan hadir. 


\subsection{Pendataan Siswa TPA Putra Bani}

TPA Putra Bani sudah beberapa tahun ini telah meluluskan putra-putri hingga lulus SMA dan saat ini masuk ke beberapa Perpuruan Tinggi, ada yang di dalam kota dan keluar kota. Adapun data terakhir nama siswa yang mengikuti pendidikan di TPA meliputi para siswa dari kelompok usia TK, SD, SMP, dan SMA dapat dilihat pada Tabel 2. sebagai berikut :

Tabel 2 Daftar Nama Siswa TPA Putra Bani

\begin{tabular}{|l|l|c|c|}
\hline No. & \multicolumn{1}{|c|}{ Nama $(*)$} & Kelompok Usia & L/P \\
\hline 1 & Faqih & TK & $\mathrm{L}$ \\
\hline 2 & Lucky & SD & $\mathrm{L}$ \\
\hline 3 & Dwi Sabila Rozaq & SD \\
\hline 4 & Falah & SD & $\mathrm{L}$ \\
\hline 5 & Wildan & SD & $\mathrm{P}$ \\
\hline 6 & Nadia & SD & $\mathrm{P}$ \\
\hline 7 & Aliyah & SMP & $\mathrm{P}$ \\
\hline 8. & Didan & SMP & $\mathrm{P}$ \\
\hline 9. & Vera & SMP & $\mathrm{P}$ \\
\hline 10. & Wilda & SMA & $\mathrm{P}$ \\
\hline 11. & Ica & SMA & $\mathrm{P}$ \\
\hline 12. & Bila & SMA & $\mathrm{P}$ \\
\hline 13. & Dinda & SMA & \\
\hline 14. & Valeria & & $\mathrm{L}$ \\
\hline
\end{tabular}

Ket. : Nama panggilan (*)

\subsection{Jadwal Rapat Lima Unsur Pendidikan}

Untuk melakukan evaluasi keberhasilan dan pengawasan jalannya kegiatan pendidikan di TPA Putra Bani telah disepakati untuk penjadwalan rapat Lima Unsur pendidikan. Lima unsur pendidikan meliputi siswa, orang tua, pengajar/ ulama, pengurus TPA, dan pakar pendidikan dari lingkungan setempat. Adapun jadwal rapat lima unsur diadakan setiap dua bulan, yaitu :

Tabel 3 Jadwal Rapat Lima Unsur Pendidikan

\begin{tabular}{|c|l|l|}
\hline No. & \multicolumn{1}{|c|}{ Acara } & \multicolumn{1}{c|}{ Jadwal Rapat } \\
\hline 1 & Rapat lima unsur pendidikan & $\begin{array}{l}\text { Dua bulan sekali } \\
\text { Januari - Maret - Mei - } \\
\text { Juli - September - Nopember }\end{array}$ \\
\hline
\end{tabular}

Keterangan : Jadwal rapat pada Minggu ke-3 
Agenda yang dibicarakan pada rapat lima unsur meliputi pembahasan laporan kehadiran siswa, perkembangan prestasi belajar siswa, serta menghimpun masukan atau saran-saran dari semua unsur untuk perbaikan dan evaluasi kegiatan TPA Putra Bani agar lebih baik lagi ke depannya.

\subsection{Kurikulum Pendidikan TPA}

Kurikulum pendidikan di TPA Putra Bani sudah menggunakan buku modul bahan pembelajaran mulai dari usia Paud, TK, SD, SMP, hingga SMA. Masingmasing modul mempunyai target pembelajaran disesuaikan dengan tingkat usia siswa. Buku modul diberikan kepada masing-masing orang tua untuk bersama-sama memantau perkembangan dan prestasi siswa apakah ada kemajuan atau masih terdapat kendala apa saja yang harus diperbaiki.

Tabel 4 Target Pembelajaran Sesuai Kurikulum

\begin{tabular}{|c|c|l|}
\hline No. & Kelompok Umur & \multicolumn{1}{|c|}{ Target Pembelajaran } \\
\hline 1 & PAUD & Menulis hijaiyah, mewarnai, dan bernyanyi \\
\hline 2 & TK & $\begin{array}{l}\text { Menulis huruf sambung, menulis angka Arab, } \\
\text { mewarnai, dan bernyanyi }\end{array}$ \\
\hline 3 & SD & $\begin{array}{l}\text { Tilawati, bacaan sholat, hafalan Asmau'ul Husnah, } \\
\text { akhlak, do'a harian. Praktek wudhu, hafalan surat } \\
\text { pendek. Tadarus Al-Qur'an, tajwid dan makhroj, } \\
\text { hadits. Makna Al-Qur'an, hafalan dalil, sholat } \\
\text { sunnah }\end{array}$ \\
\hline 4 & SMP & $\begin{array}{l}\text { Tadarus Al-Qur'an Juz 1-5, hafalan ayat pilihan, } \\
\text { adzan/ iqomah }\end{array}$ \\
\hline 5 & SMA & $\begin{array}{l}\text { Tadarus dan makna Al-Qur'an s/d Al-Imron. } \\
\text { Makna hadits Kitabul Ahkam, hafalah surat Al- } \\
\text { Baqarah. Praktek nasihat dan mengajar }\end{array}$ \\
\hline
\end{tabular}

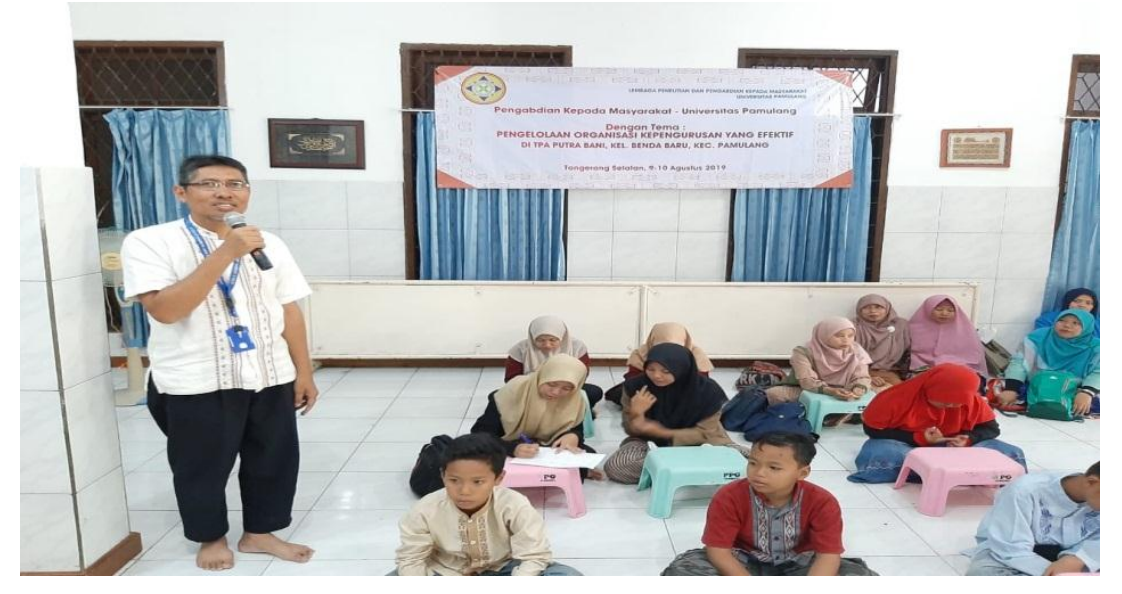

Gambar 3 Acara Penyuluhan 


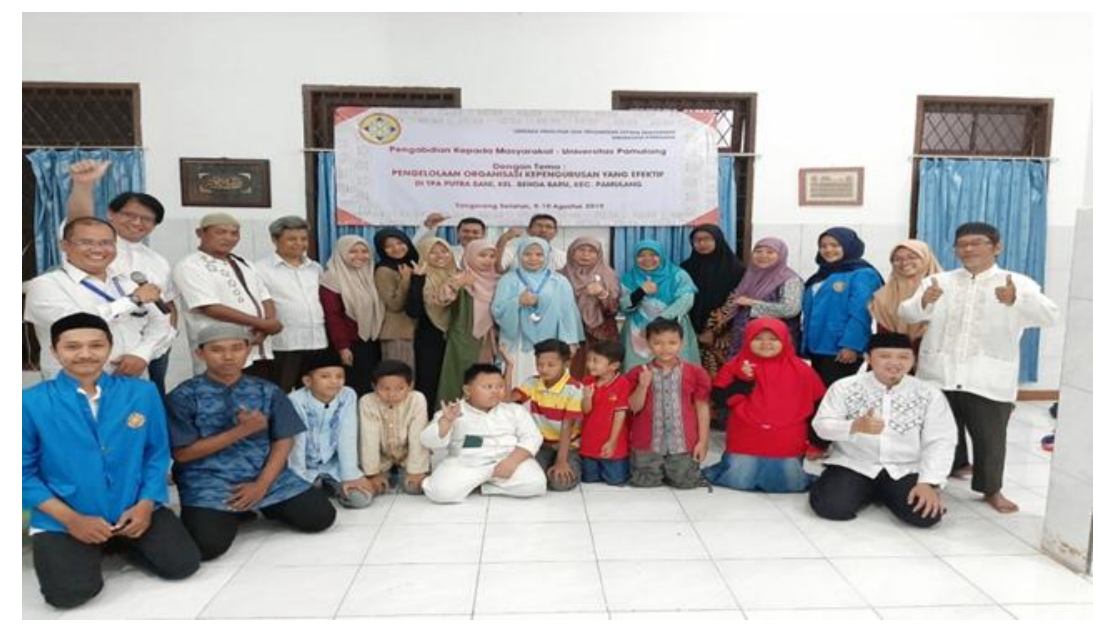

Gambar 4 Berfoto dengan siswa, orang tua, pengajar, dan pengurus TPA Putra Bani

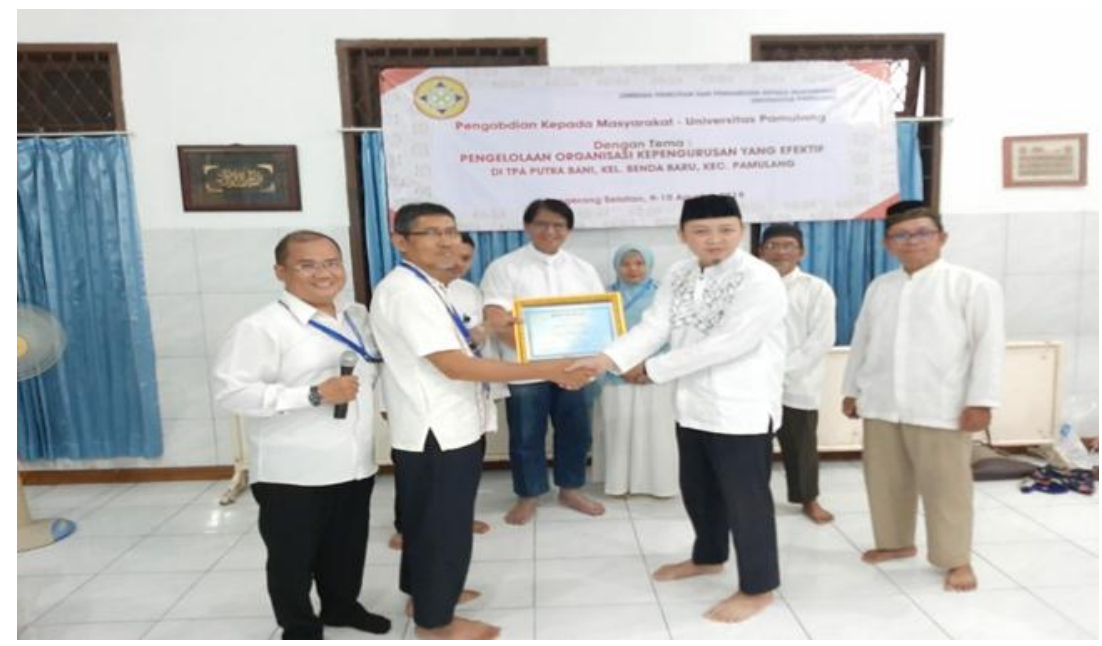

Gambar 5 Penyerahan Cindera Mata

\section{SIMPULAN}

Pada kegiatan pengabdian kepada masyarakat ini dosen Universitas Pamulang telah memberikan kontribusi positif berupa penyuluhan dan pelatihan bagi upaya peningkatan pengelolaan organisasi yang efektif terhadap TPA Putra Bani. Pada kegiatan pengabdian diperoleh hasil sebagai berikut :

1). Pembentukan susunan pengurus TPA Putra Bani

2). Pendataan siswa dari usia TK, SD, SMP, dan SMA

3). Penjadwalan rapat lima unsur pendidikan

4). Sosialisasi kurikulum dan target pembelajaran masing-masing kelompok usia

Adapun saran-saran yang dapat tim pengabdi sampaikan adalah:

1). Masing-masing pengurus TPA Putra Bani agar dapat berperan sesuai dengan tugasnya masing-masing, agar penyelenggaran TPA dapat berjalan dengan baik dan efektif, sesuai sasaran yang diharapkan. 
2). Data siswa agar dilakukan lebih rinci lagi terutama data nama lengkap siswa, nama orang tua, dan alamat siswa

3). Rapat lima unsur pendidikan dijadwalkan setiap dua bulan sekali, tetapi jika terdapat keperluan dan tujuan tertentu dapat dilakukan mendadak di luar jadwal.

4). Orang tua hendaknya terus memahami target pembelajaran yang sudah disediakan sesuai kurikulum, agar membantu evaluasi disamping penilaian dari pengajar.

5). Perlu adanya pelaksanaan kegiatan pengabdian masyarakat yang berkelanjutan untuk mengkaji kembali materi yang telah disampaikan pada PKM ini.

\section{DAFTAR PUSTAKA}

Agus Priyono. (2019). Mengelola Organisasi Efektif. Universitas Setia Budi. Academia education.

Fadhil Akbar Kurniawan. (2016). 7 Hal Yang Harus Diperhatikan Dalam Membangun Koordinasi Yang Baik Dalam Pengembangan Organisasi. Hipwee Community.

Reza Maulana. (2017). Motivasi Siswa SMAN-1 Kota Jantho Dalam Membaca AlQur'an. Universitas Islam Negeri Ar-Raniry Darussalam, Banda Aceh.

Rita Mariyana. (2019). Unsur-unsur Yang Berperan Penting Dalam Pengelolaan Lingkungan Bekerja Universitas Pendidikan Indonesia.

Septiady. (2019). Organisasi, Pengerrtian, Tujuan, Struktur, Fungsi, dan Unsur. Crypto Harian.

Vivi Aisyahlani Putri. (2017). Peran Taman Pendidikan Al-Qur'an (TPA) Dalam Penyelenggaraan Pendidikan Al-Qur'an Di Masjid Al-Fatta S ekip Ujung Palembang. Universitas Islam Negeri Raden Fattah, Pelembang. 